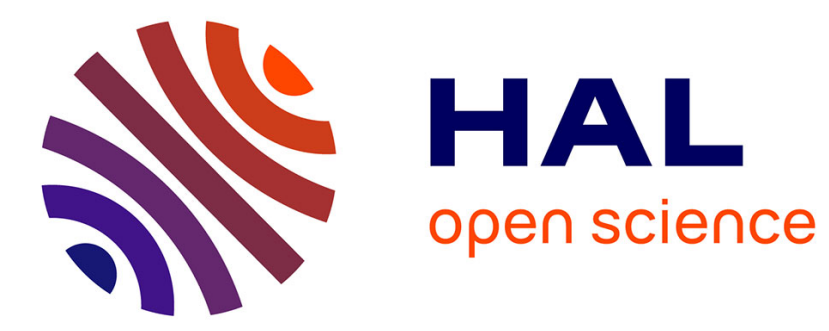

\title{
The contact density for a distribution of randomly packed spheres
}

E. Gardner

\section{To cite this version:}

E. Gardner. The contact density for a distribution of randomly packed spheres. Journal de Physique, 1985, 46 (10), pp.1655-1656. 10.1051/jphys:0198500460100165500 . jpa-00210113

\section{HAL Id: jpa-00210113 https://hal.science/jpa-00210113}

Submitted on 1 Jan 1985

HAL is a multi-disciplinary open access archive for the deposit and dissemination of scientific research documents, whether they are published or not. The documents may come from teaching and research institutions in France or abroad, or from public or private research centers.
L'archive ouverte pluridisciplinaire HAL, est destinée au dépôt et à la diffusion de documents scientifiques de niveau recherche, publiés ou non, émanant des établissements d'enseignement et de recherche français ou étrangers, des laboratoires publics ou privés. 
Classification

Physics Abstracts

46.30

\title{
The contact density for a distribution of randomly packed spheres
}

\author{
E. Gardner \\ Service de Physique Théorique, CEA-Saclay, Orme des Merisiers, 91190 Gif sur Yvette Cedex, France
}

(Reçu le 1er octobre 1984, révisé le 7 juin 1985, accepté le 13 juin 1985)

\begin{abstract}
Résumé. - La densité de contacts entre des sphères empilées de façon aléatoire est calculée à l'aide de résultats obtenus sur une droite.
\end{abstract}

\begin{abstract}
The density of contacts between randomly packed spheres is calculated in terms of data given on a random line.
\end{abstract}

Information about the distribution and shapes of close-packed objects can be obtained from observations on a random line or section through the material [1]. This is useful for example in determining the grain structure of metals from electron microscope studies of two-dimensional cross-sections, in studying percolation properties of rocks and elasticity and conductivity properties of amorphous materials.

Distributions of hard spheres can be used to model percolation properties of disordered systems [6-8]. In this paper, a homogeneous distribution of spheres will be considered and the density of contacts between spheres per unit occupied volume will be found in terms of the density of " close " contacts observed along a random line through the material.

For [2] a homogeneous distribution of spheres, the number of spheres of radius between $R$ and $R+\mathrm{d} R$, per unit occupied volume, $n(R) \mathrm{d} R$ can be calculated in terms of $h(\lambda) \mathrm{d} \lambda$, the number of chords per unit length on a random line with length between $\lambda$ and $\lambda+\mathrm{d} \lambda$.

$n(R)$ is given by

$$
n(R)=-\frac{1}{\pi} \frac{\mathrm{d}}{\mathrm{d} R}\left(\frac{h(2 R)}{R}\right)
$$

This formula is simpler than the corresponding formula for random sections which relates $n(R)$ to the density of circles on the cross section through an Abel transform [2].

In the following, the distribution $P\left(R_{1}, R_{2}\right) \mathrm{d} R_{1} \mathrm{~d} R_{2}$ of spheres of radii between $R_{1}$ and $R_{1}+\mathrm{d} R_{1}$ and between $R_{2}$ and $R_{2}+\mathrm{d} R_{2}$ in contact with one another per unit volume will be determined in terms of information given on a random line. The calculation is similar to one by Pomeau [3, 4] for the case of random sections. One considers the distribution per unit length $P\left(\omega, d_{1}, d_{2}\right)$ of neighbouring chords of lengths $d_{1}$ and $d_{2}$ on the line with separation $\omega$. For sufficiently small $\omega$, such a situation implies that there is a contact between the two spheres close to the line. It will turn out that $P\left(\omega, d_{1}, d_{2}\right)$ does not depend on $\omega$ for small $\omega$ and that $P(R, \alpha R)$ is related to $P(\omega, 2 R$, $2 \alpha R)$ by

$P(R, \alpha R)=-\frac{8}{\pi} R \frac{\mathrm{d}}{\mathrm{d} R}\left(\frac{P(\omega, 2 R, 2 \alpha R)}{R}\right)\left(\frac{\alpha+1}{\alpha}\right)$

and the density of contacts between spheres per unit occupied volume, $n_{\mathrm{c}}$ is given by

$$
n_{\mathrm{c}}=\frac{12 Q(0)}{\pi R}
$$

where $Q(\omega)$ is the density of " close " contacts along the line. $P\left(\omega, d_{1}, d_{2}\right)$ and $Q(\omega)$ are independent of $\omega$ as $\omega \rightarrow 0$ in contrast to the case of random sections [3] where both distributions diverge as $1 / \sqrt{\omega}$ as $\omega \rightarrow 0$ and $P(R, \alpha R)$ is related to the distribution of separations and radii of intersected spheres through an Abel transform.

In figure $1, \mathrm{O}_{1}$ and $\mathrm{O}_{2}$ are the centres of the two spheres of radii $R_{1}$ and $R_{2}$ respectively. The lines $\mathrm{O}_{1} \mathrm{O}_{2}$ and the random line $G$ have a common normal. $\mathrm{H}_{1} \mathrm{H}_{2}$ is the projection of $G$ by a distance $l$ along this normal onto the plane of $\mathrm{O}_{1} \mathrm{O}_{2}$.

The cross sections of the spheres on this plane are circles of radii $d_{1}^{\prime} / 2$ and $d_{2}^{\prime} / 2$. The contact at $\mathrm{C}$ is at a height $d$ and angle $\theta$ above $\mathrm{H}_{1} \mathrm{H}_{2}$. This implies, for small enough $d$ and $l$ that a close separation $\omega_{1}^{\prime} \omega_{2}^{\prime}$ is observed on the line $\mathrm{G}$. 
From figure 1,

$$
\begin{aligned}
\mathrm{H}_{1}^{\prime} \mathrm{H}_{2}^{\prime} & =\mathrm{H}_{1} \mathrm{H}_{2}=\sqrt{\left(R_{1}+R_{2}\right)^{2}-\left(h_{1}+h_{2}\right)^{2}} \\
d_{1} / 2 & =\omega_{1}^{\prime} \mathrm{H}_{1}^{\prime}=\sqrt{R_{1}^{2}-h_{1}^{2}-l^{2}} \\
d_{2} / 2 & =\omega_{2}^{\prime} \mathrm{H}_{2}^{\prime}=\sqrt{R_{2}^{2}-h_{2}^{2}-l^{2}} .
\end{aligned}
$$

For small $d$ and $l$,

$$
\omega=\omega_{1}^{\prime} \omega_{2}^{\prime}=\frac{1}{2}\left(\frac{1}{R_{1}}+\frac{1}{R_{2}}\right)\left(\frac{d^{2}}{\cos ^{3} \theta}+\frac{l^{2}}{\cos \theta}\right) .
$$

For a homogeneous distribution, the line of separation between the centres $\mathrm{O}_{1} \mathrm{O}_{2}$ is randomly oriented with respect to $\mathrm{G}$.

Therefore,

$$
\begin{gathered}
P\left(\omega, d_{1}, d_{2}\right)=\int_{0}^{\infty} \mathrm{d} l \int_{0}^{\infty} \mathrm{d} d \int_{0}^{\pi / 2} \sin \theta \mathrm{d} \theta \times \\
\quad \times \int_{0}^{\infty} \mathrm{d} R_{1} \int_{0}^{\infty} \mathrm{d} R_{2} P\left(R_{1}, R_{2}\right) \\
\delta\left(d_{1}-2 R_{1} \cos \theta\right) \delta\left(d_{2}-2 R_{2} \cos \theta\right) \\
\delta\left(\omega-\frac{1}{2}\left(\frac{1}{R_{1}}+\frac{1}{R_{2}}\right)\left(\frac{d^{2}}{\cos ^{3} \theta}+\frac{l^{2}}{\cos \theta}\right)\right)= \\
=\frac{\pi}{16} \frac{d_{1} d_{2}}{d_{1}+d_{2}} \int_{1}^{\infty} \frac{P\left(d_{1} x / 2, d_{2} x / 2\right)}{x} \mathrm{~d} x
\end{gathered}
$$

and so $P\left(\omega, d_{1}, d_{2}\right)$ is independent of $\omega$ for small $\omega$.

For the case of equal spheres, one can set

$$
P\left(\frac{d_{1}}{2} x, \frac{d_{2}}{2} x\right)=n_{\mathrm{c}} \delta\left(\frac{d_{1}}{2} x-R\right) \delta\left(\frac{d_{2}}{2} x-R\right)
$$

where $n_{\mathrm{c}}$ is the number of contacts per unit volume.

Then,

$$
P\left(\omega, d_{1}, d_{2}\right)=n_{\mathrm{c}} \delta\left(d_{1}-d_{2}\right) \frac{\pi}{32} \frac{d_{1}^{2}}{R^{2}}
$$

Integrating $d_{1}$ and $d_{2}$ from 0 to $2 R$ gives a simple

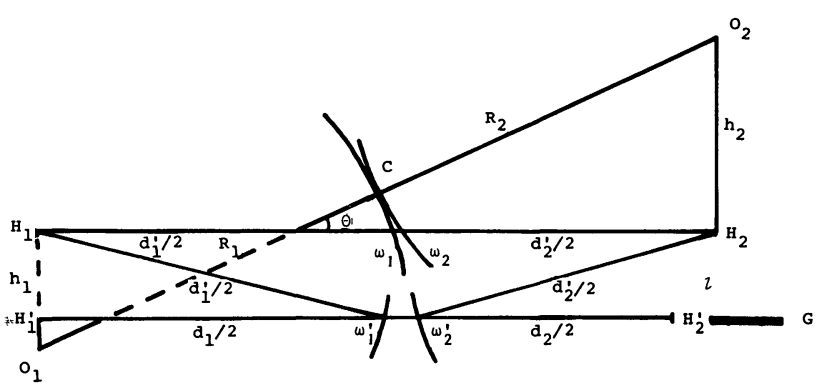

Fig. 1. - The plane of the line $\mathrm{O}_{1} \mathrm{O}_{2}$ containing the projection $\mathrm{H}_{1} \mathrm{H}_{2}$ of the random line $\mathrm{G}$ along their common normal and the plane normal to this one containing $\mathrm{G}$ and $\mathrm{H}_{1} \mathrm{H}_{2} . \mathrm{O}_{1} \mathrm{C}=R_{1}, \mathrm{O}_{2} \mathrm{C}=R_{2}, \mathrm{O}_{1} \mathrm{H}_{1}=h_{1}, \mathrm{O}_{2} \mathrm{H}_{2}=h_{2}$, $\mathbf{H}_{1} \mathbf{H}_{1}^{\prime}=\mathbf{H}_{2} \mathbf{H}_{2}^{\prime}=R, \mathbf{H}_{1} \omega_{1}=\mathbf{H}_{1} \omega_{1}^{\prime}=d_{1}^{\prime} / 2, \mathbf{H}_{2} \omega_{2}=$ $\mathbf{H}_{2} \omega_{2}^{\prime}=d_{2}^{\prime} / 2, \mathbf{H}_{1}^{\prime} \omega_{1}^{\prime}=d_{1} / 2, \mathrm{H}_{2}^{\prime} \omega_{2}^{\prime}=d_{2} / 2$.

relation between the number of close separations per unit length $Q(\omega)$ and $n_{\mathrm{c}}$,

$$
Q(\omega)=\frac{\pi n_{\mathrm{c}}}{12} R .
$$

Equation (8) can be inverted to obtain $P(R, \alpha R)$ for a distribution of spheres of different sizes. This leads to the result stated in equation (2).

It would be interesting to extend this result to calculate correlation functions between contacts along the line for situations in which there is long range order [5]. One would also like to generalize to distributions of objects of arbitrary shape. Provided the assumption that a sufficiently close separation on the line implies a real contact close to the line, this can be obtained from a knowledge of number of chords of given length through the object and the shape of the object near the end points of the chord.

\section{Acknowledgments.}

I would like thank C. Itzykson and Y. Pomeau for helpful comments. I am also grateful to the Royal Society for financial support.

\section{References}

[1] UNDERWOOD, E. E., Quantitative Stereology (Addison Wesley) (1969).

[2] Santalo, L. A., Integral Geometry and Geometric Probability (Addison Wesley) (1976).

[3] Pomeau, Y., Ann. Inst. Henri Poincaré XXXVIII (1983) 75.

[4] Pomeau, Y. (1984) Preprint.
[5] Zallen, R., in Fluctuation Phenomena, Studies in Statistical Mechanics VII (North Holland) (1979).

[6] Scher, H., Zallen, R., J. Chem. Phys. 53 (1970) 3759.

[7] Pike, G. E., Seager, C. H., Phys. Rev. B 10 (1974) 1421.

[8] Ottavi, H., Clerc, J., Giraud, G., RoussenQ, J., Guyon, E., Mitescu, C. D., J. Phys. C 11 (1978) 1311. 